\title{
Steady-State Analysis and Output Voltage Minimization Based Control Strategy for Electric Springs in the Smart Grid with Multiple Renewable Energy Sources
}

\author{
Yun Zou $\mathbb{D}^{1},{ }^{1}$ Michael Z. Q. Chen $\mathbb{D}^{1},{ }^{1}$ Yinlong $\mathrm{Hu} \mathbb{D},{ }^{2}$ and Yun Zou $\mathbb{D}^{1}$ \\ ${ }^{1}$ School of Automation, Nanjing University of Science and Technology, Nanjing 210094, China \\ ${ }^{2}$ College of Energy and Electrical Engineering, Hohai University, Nanjing 210098, China \\ Correspondence should be addressed to Michael Z. Q. Chen; mzqchen@outlook.com
}

Received 21 February 2019; Revised 1 April 2019; Accepted 8 April 2019; Published 9 May 2019

Guest Editor: Chun Wei

Copyright (C) 2019 Yun Zou et al. This is an open access article distributed under the Creative Commons Attribution License, which permits unrestricted use, distribution, and reproduction in any medium, provided the original work is properly cited.

\begin{abstract}
This paper presents a general steady-state analysis and proposes a minimal compensating voltage (MCV) control scheme for the second generation of electric springs (ES-2) in the power system with substantial penetration of intermittent renewable energy sources. For the steady-state analysis, the relationship among the fluctuating part of the supply voltage, the voltage at the point of common-coupling (PCC), and the compensating voltage provided by ES-2 is derived, which implies that the phase angle related to the PCC voltage can be used as a degree of freedom for the control design to obtain a minimal compensating voltage in a given system. Such a fact is utilized in the control design to obtain the reference of PCC voltage by tuning the above-mentioned phase angle. Once the phase angle of the PCC voltage is chosen, the maximal compensating voltage can be estimated based on the fluctuating part of the supply voltage which can be estimated a priori. Such a fact can be used to design suitable electric springs with appropriate compensating capacity to avoid overcapacity. Numerical simulations are conducted to verify the effectiveness of the steady-state analysis and the proposed control scheme for ES-2.
\end{abstract}

\section{Introduction}

In recent years, due to the energy crisis and the increasingly severe environmental issues, renewable energy sources are attracting more and more attention. Nowadays, wind [1-3] and solar energies are the two most widely used renewable energy sources for distributed generation [4-6]. However, due to the highly intermittent and unpredictable natures, renewable energy power generation brings a series of challenges to the power grid. Imbalance between the power supply and demand is one of the most prominent problems [7], which will cause the fluctuations of frequencies and voltages. Therefore, demand-side management has become a significant topic in the smart grid with intermittent renewable energy sources $[8,9]$.

Electric spring (ES) was first introduced in 2012 as a new generation of smart grid $[10,11]$ technology aiming to automatically balance the power generation and load demand without relying on the information and communication technology [12]. Generally speaking, ESs can be mainly divided into two categories. The first type called ES-1 works as a purely reactive power compensator to regulate the PCC voltage, while keeping the power consumption at the load side to be consistent with the power generation in real time. Examples of relevant research work on ES-1 are as follows. Dynamic modeling of ES and the influence of load ratios on compensation effects are described in [13]. Hardware and control implementation based on theoretical analysis are illustrated in [14]. Droop control and consensus control used to regulate the voltage by distributed ESs in the future smart grid are introduced in [15] and [16], respectively. However, just as a physical spring has limits for tension and compression, ES-1 also has its own compensation limits, exceeding which ES-1 will be invalidated. ES-2, which can provide six more operating modes in addition to the capacitive and inductive modes [17], can make up for these shortcomings. The difference in the topological structure between ES-1 and ES-2 is that the DC-link capacity in 


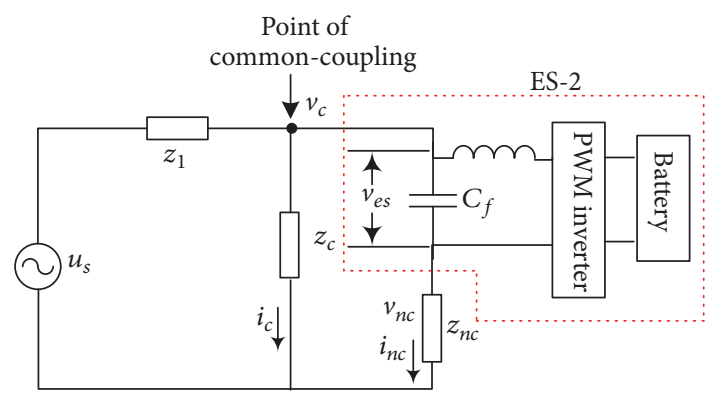

FIgURE 1: Simplified schematic of the power system with ES-2.

ES-1 is replaced by energy storage systems (such as batteries) on the DC side of the inverter in ES-2, thus the voltage phase angle of ES-2 is not restricted to be 90 degrees with respect to its current. At present, some research results of theoretical analysis and control schemes for ES-2 have been obtained. Regulating voltage and improving power quality (e.g., power factor correction and harmonics reduction) at the same time by ES-2 are introduced in [18], which are not possible with ES-1. In [19], a novel control strategy named $\delta$ control is proposed to obtain the instantaneous phase of PCC voltage to achieve specific power factor correction and constant power compensation. In [20], a radial-chordal decomposition (RCD) approach for ES-2 to regulate the PCC voltage is introduced, which can concurrently realize power factor correction by independent control of active and reactive powers.

However, these control strategies ignore the effect on ES2 its own output value while focusing on the compensation functions. Note that it is meaningful to avoid overcapacity in terms of cost reduction in practice, and for ES-2, the relationship among the fluctuating part of the supply voltage, the PCC voltage, and the voltage provided by ES- 2 is significant for determining the compensation capacity of electric springs. Therefore, in this paper, a general steadystate analysis for ES-2 is carried out to algebraically derive this relationship, which is depicted in a vector diagram. Based on the vector diagram, the detailed impact on compensating voltage caused by the fluctuating part of the supply voltage and a specific phase angle related to the PCC voltage is analyzed. Moreover, a control strategy to obtain the minimal compensating voltage (MCV) is proposed, the effectiveness of which is demonstrated by numerical simulations. These constitute the main contributions of this paper.

The rest of this paper is organized as follows. In Section 2, the operating principle of ES for the future smart grid is described. Sections 3 and 4 analyze the steady-state based on the vector diagram and propose a control scheme for ES-2, respectively. Numerical simulations are presented in Section 5 to verify the effectiveness of the analysis and the control scheme. Section 6 draws the conclusions.

\section{Operation Principles of Electric Springs}

Figure 1 shows a simplified schematic of the power system that is composed of an ES, noncritical loads, critical loads, a fluctuating AC voltage source, and transmission lines. One thing to note is that the noncritical loads can withstand a wide range of voltage fluctuation, while the critical loads are sensitive to voltage fluctuation. The ES shown in the red dashed box of Figure 1 mainly consists of an energy storage system (represented by batteries), a single-phase inverter [2126], and an LC filter as a second-order low-pass filter to reduce the switching harmonics. The output of the ES is connected to the noncritical load $z_{n c}$ to form a smart load. The critical load $z_{c}$ and the smart load connect to the supply voltage source through the line impedance $z_{1}$. The voltages across the noncritical load and the filter capacitor $C_{f}$ are represented as $v_{n c}$ and $v_{e s}$, respectively. $i_{n c}$ denotes the current flowing through the noncritical load. The supply voltage source denoted by $u_{s}$ in Figure 1 can be represented as follows:

$$
u_{s}=u_{f}+\Delta u \text {, }
$$

where $u_{f}$ represents the voltage corresponding to the power generated by the power plant, which is stable and controllable, while $\Delta u$ denotes the fluctuating part of the supply voltage caused by intermittent renewable energy sources, which is unstable and unpredictable. As the proportion of renewable energy connected to the power grid increases, $\Delta u$ will increase correspondingly. Due to the requirements of being grid-connected, $u_{f}$ and $\Delta u$ will have the same frequency and phase angle.

Because of the randomness of renewable energy, the power delivered to the network is unstable. When exceeding the demand, the PCC voltage will be over the rated value, vice versa. For a change in $\Delta u$, ES will provide a corresponding compensating voltage $v_{e s}$ to keep the PCC voltage stable. In this way, the power generation and load demand can be balanced automatically, which is different from the existing control paradigm that the power generation should follow load demand.

Note that the ES-2 as shown in Figure 1 is equipped with batteries on the DC side of the inverter. The phase angle of the voltage provided by ES- 2 is not limited to 90 degrees (lag or lead) with respect to the phase angle of $i_{n c}$. Therefore, active power can be provided in addition to reactive power. And for this reason, ES-2 has a larger compensation rang compared to ES-1. Consequently, new control strategies are required due to the structural change mentioned above, which will be described in detail in Section 4.

\section{Steady-State Analysis of Electric Springs for Minimal Compensating Voltage}

From Figure 1 and Kirchhoff's voltage and current laws, one obtains

$$
\begin{aligned}
& v_{c}=v_{e s}+v_{n c}, \\
& v_{n c}=z_{n c} \cdot\left(\frac{u_{s}-v_{c}}{z_{1}}-\frac{v_{c}}{z_{c}}\right), \\
& z_{1}=R_{1}+j \omega L_{1},
\end{aligned}
$$

where $R_{1}$ and $L_{1}$ are the equivalent resistance and inductance of the transmission lines, respectively. 


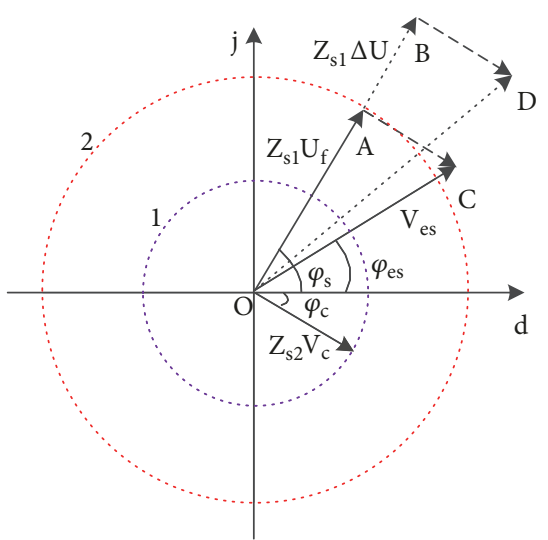

FIGURE 2: General vector diagram of a power system.

Solving (1)-(3), one obtains

$$
\begin{aligned}
& v_{e s}=z_{s 1} \cdot u_{f}+z_{s 1} \cdot \Delta u+z_{s 2} \cdot v_{c}, \\
& z_{s 1}=-\frac{z_{n c}}{z_{1}}, \\
& z_{s 2}=1+\frac{z_{n c}}{z_{1}}+\frac{z_{n c}}{z_{c}}
\end{aligned}
$$

where $z_{s 1}$ and $z_{s 2}$ are determined by the parameters of the circuit elements which can be treated as constant values for a given system.

Equation (5) can be represented in the phasor form as

$$
\begin{aligned}
& V_{e s} \angle \varphi_{e s}=Z_{s 1} U_{f} \angle \varphi_{s}+Z_{s 1} \Delta U \angle \varphi_{s}+Z_{s 2} V_{c} \angle \varphi_{c}, \\
& \varphi_{s}=\varphi_{s 1}+\varphi_{s 3}, \\
& \varphi_{c}=\varphi_{s 2}+\varphi_{c 1}, \\
& \Delta \varphi=\varphi_{s}-\varphi_{c}, \\
& U_{s}=U_{f}+\Delta U, \\
& V_{e s}=\sqrt{\left(Z_{s 2} V_{c}+Z_{s 1} U_{s} \cos \Delta \varphi\right)^{2}+\left(Z_{s 1} U_{s} \sin \Delta \varphi\right)^{2}},
\end{aligned}
$$

where $Z_{s i}$ and $\varphi_{s i}$ are the magnitude and the displacement angle of $z_{s i}(i=1,2)$, respectively. $V_{e s}, V_{c}, U_{f}$, and $\Delta U$ are the root-mean-square (RMS) values of $v_{e s}, v_{c}, u_{f}$, and $\Delta u$, respectively, and $\varphi_{e s}, \varphi_{c 1}$, and $\varphi_{s 3}$ are the phase angles of $v_{e s}$, $v_{c}$, and $u_{s}$, respectively. $\Delta \varphi$ denotes the difference between $\varphi_{s}$ and $\varphi_{c}$, which is related to $\varphi_{s 3}$ and $\varphi_{c 1}$ due to the fact that $\varphi_{s 1}$ and $\varphi_{s 2}$ are constants in a given system. The vector diagram among $v_{e s}, z_{s 1} u_{f}, z_{s 1} \Delta u$, and $z_{s 2} v_{c}$ is depicted in Figure 2. Since the PCC voltage (i.e., $v_{c}$ ) is maintained at its nominal reference level (e.g., $220 \mathrm{~V}$ ), then $Z_{s 2} V_{c}$ is a constant as the circle 1 showed in Figure 2. Similarly, $Z_{s 1} U_{f}$ on the circle 2 represented by the solid line OA can be treated as a constant as well. The fluctuating part of the source voltage $(\Delta U)$ multiplied by $Z_{s 1}$ is represented by the dashed line $\mathrm{AB}$. For a constant $\Delta \varphi$, if $Z_{s 1} \Delta U$ changes from point $\mathrm{A}$ to point $\mathrm{B}$, the compensating voltage $v_{e s}$ will change from line OC to line OD, correspondingly.

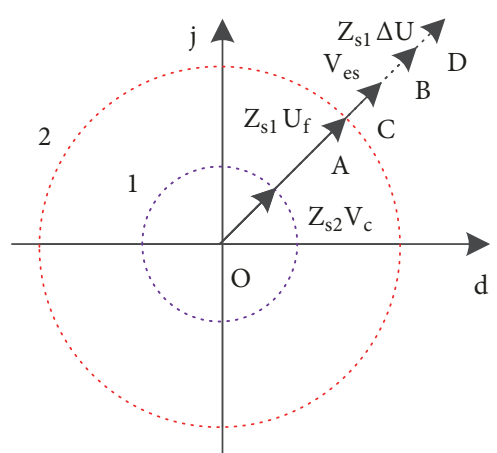

(a)

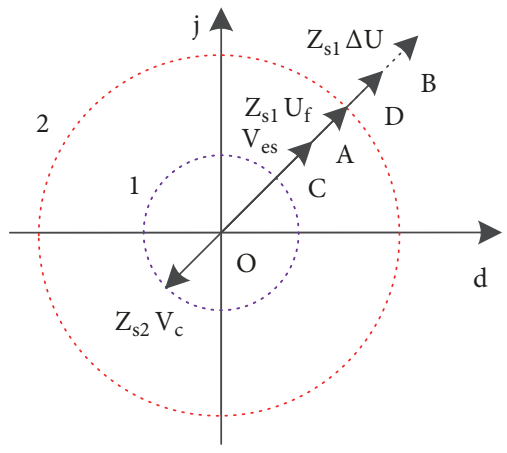

(b)

FIGURE 3: Vector diagram of the power system. (a) $\Delta \varphi=0$; (b) $\Delta \varphi=$ $\pi$.

TABLE 1: Simulated test system parameters.

\begin{tabular}{lc}
\hline Item & Value \\
\hline line resistance $R_{1}$ & $0.1 \Omega$ \\
line inductance $L_{1}$ & $2.4 \mathrm{mH}$ \\
Critical load $z_{c}$ & $8 \Omega$ \\
Non-critical load $z_{n c}$ & $8 \Omega$ \\
Predefined reference value $V_{c-r e f}$ & $220 \mathrm{~V}$ \\
Base voltage $U_{f}$ & $210 \mathrm{~V}$ \\
\hline
\end{tabular}

$*$ Parameters come from [27]

From Figure 2, one sees that $\Delta U, \Delta \varphi$ are the two essential factors for $v_{e s}$. Especially, if $\Delta \varphi=0$, namely, $z_{s 1} u_{s}$ and $z_{s 2} v_{c}$ have the same phase angle, a maximal $V_{e s}$ will be obtained as shown in Figure 3(a). In contrast, a minimal $V_{e s}$ can be obtained with $\Delta \varphi=\pi$ as shown in Figure 3(b).

To quantitatively show the influence of $\Delta U$ and $\Delta \varphi$ on $V_{e s}$, the parameters in Table 1 are employed. A three-dimensional representation among $\Delta U, \Delta \varphi$, and $V_{e s}$ is given in Figure 4, where one sees that the minimal value of $V_{e s}$ is obtained at $\Delta \varphi=\pi$. Table 2 shows some representative values of $\Delta U, \Delta \varphi$ and the corresponding $V_{e s}$ based on the parameters in Table 1 . One sees that $V_{e s}$ is highly influenced by $\Delta \varphi$. For example, when $\Delta \varphi$ changes from $\pi$ to 0 , the variation percentages of $V_{e s}$ are up to 2177.64 for the cases $\Delta U=0$. All the variation percentages shown in Table 2 are based on the values obtained at $\Delta \varphi=\pi$, where positive values indicate increment. 
TABLE 2: Quantitative comparisons for different $\Delta \varphi$ and $\Delta U$.

\begin{tabular}{lccc}
\hline & $\Delta U=0$ & $\Delta U=30 \mathrm{~V}$ & $\Delta U=50 \mathrm{~V}$ \\
\hline$\Delta \varphi$ & $V_{e s}(\mathrm{~V})$ & $V_{e s}(\mathrm{~V})$ & $V_{e s}(\mathrm{~V})$ \\
\hline 0 & 4620.42 & 4935.96 & 5146.32 \\
& $2177.64 \%$ & $4280.51 \%$ & $1493.10 \%$ \\
\hline$\frac{1}{3} \pi$ & 4002.69 & 4275.04 & 4459.77 \\
\hline$\frac{1}{2} \pi$ & $1873.13 \%$ & $3693.97 \%$ & $1280.56 \%$ \\
\hline 2 & 3270.28 & 3491.16 & 3646.16 \\
$\frac{3}{3} \pi$ & $1512.09 \%$ & $2998.30 \%$ & $1028.70 \%$ \\
\hline$\pi$ & 2316.88 & 2469.91 & 2588.32 \\
\hline & $1042.11 \%$ & $2091.97 \%$ & $701.24 \%$ \\
\hline
\end{tabular}

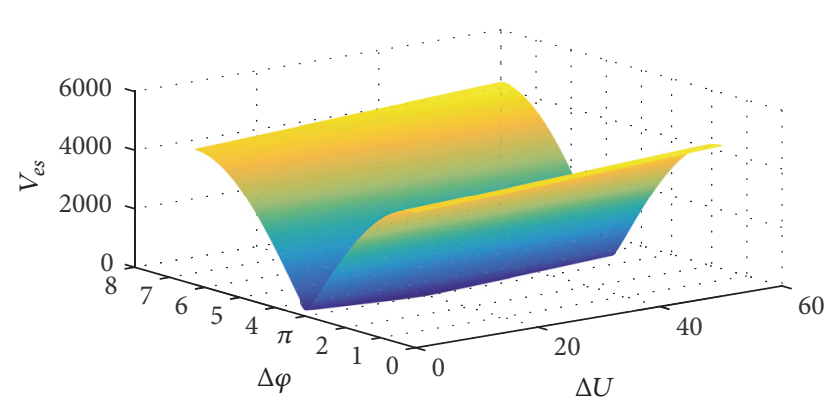

FIgURE 4: Three-dimensional relationships among $\Delta U, \Delta \varphi$, and $V_{e s}$.

In conclusion, $\Delta \varphi$ has a significant influence on $V_{e s}$. In other words, $V_{e s}$ is so sensitive to the phase angle $\varphi_{c 1}$, which implies that the phase angle of $v_{c-r e f}$ should be carefully selected when designing the proper control law for ES-2. If an appropriate phase angle has been chosen, then $V_{e s}$ is only determined by $\Delta U$. Since the proportion of the intermittent renewable source injected to the power grid is limited, $\Delta U$ will fluctuate within a certain range. Once $\Delta U$ can be estimated in advance, the required voltage $V_{e s}$ can also be estimated. This provides guidelines for designing suitable ESs with appropriate compensating capabilities to avoid overcapacity.

\section{Control Design for ES-2}

The aim of control design is to minimize the error between the PCC voltage and its reference $v_{c-r e f}$ by a minimal ES voltage. In this paper, to show the effectiveness of the analysis in the Section 3, a minimal compensating voltage (MCV) based control strategy is proposed for ES-2 and a proportional resonant (PR) controller is employed because of the characteristic that PR control can track a sinusoidal signal with a zero steady-state error.

Figure 5 shows the system block diagram, where the red dotted box at the bottom of the figure shows how to obtain the reference signal $v_{c-r e f}$. As can be seen from the steadystate analysis in Section 3, the magnitude of $v_{e s}$ is related to $\Delta \varphi$ and $\Delta U$, so $\Delta \varphi$ can be treated as a degree of freedom for control design to obtain a minimal value of $V_{e s}$. Since $\Delta \varphi$ is related to the phase angle of $v_{c}$ (see (9)-(11)), the key point of the proposed control strategy is transformed to select an appropriate phase angle of $v_{c-r e f}$. The supply voltage signal $u_{s}$ is obtained by a sensor, and a single-phase lock loop (PLL) is used to acquire its phase angle $\varphi_{s 3}$. Then $\varphi_{c 1}$ can be calculated through (9)-(11) based on the circuit parameters and $\varphi_{s 3}$. One remark is that the value of arctan function belongs to the interval $(-\pi / 2, \pi / 2)$, which is corresponding to the argument of a complex number whose real part is positive. If the real part of the complex number is negative, then one need to add $\pi$ when calculating the argument of a complex number, where care should be taken when calculating $\varphi_{s 1}$ and $\varphi_{s 2}$. Thus, the complete reference signal can be obtained by combining the magnitude $V_{c-r e f}$ and the phase angle $\varphi_{c 1}$. The expression of the PR controller used in this paper is as follows:

$$
G(s)=K_{p}+\frac{K_{R} s}{s^{2}+\omega^{2}}
$$

where $\omega$ is the angular frequency of the grid and $K_{p}$ and $K_{R}$ are the proportionality coefficient and resonance coefficient, respectively.

Equation (14) is an ideal PR controller, which has an infinite gain at angular frequency $\omega$, but no phase transition and gain at other frequencies. Therefore, it can realize tracking a sinusoidal signal without any steady-state error. For this reason, a PR controller is introduced to regulate the PCC voltage $\left(v_{c}\right)$ to its reference level by driving the difference between reference voltage $v_{c-r e f}$ and measured voltage $v_{c}$ to zero. In addition to PR control, many other control methods, such as sliding-mode control $[28,29]$, robust control [30], model predictive control $[31,32]$, and event-triggered control [33] can also be considered in future studies based on the control strategy mentioned above.

\section{Simulations and Discussions}

To double verify the effectiveness of the aforementioned analysis and the MCV control strategy, simulations are conducted by using MATLAB/Simulink and LabVIEW/PXI based on the parameters shown in Table 1. Without loss of generality, the RMS of $v_{c}$ is assumed to be $220 \mathrm{~V}$.

\subsection{The Simulations Conducted on MATLAB/Simulink}

5.1.1. Voltage Support Mode with $\Delta U=0 \mathrm{~V}$. In this case study, the effect of different $\Delta \varphi$ on $V_{e s}$ for voltage boosting is investigated. $\Delta U$ is set 0 to simulate insufficient output of power generation, so it can be seen that the RMS of the line voltage $v_{c}$ is less than $220 \mathrm{~V}$ with the ES-2 deactivated from Figure 6. In order to restore $V_{c}$ back to $220 \mathrm{~V}$, ES-2 should play the role of voltage support. In the voltage support mode, different values of $\Delta \varphi$ are employed to verify the influence of $\Delta \varphi$ on $V_{e s}$. The RMS of the compensating voltage $v_{e s}$ provided by ES-2 to regulate $V_{c}$ at $220 \mathrm{~V}$ are considerably different as shown in Figure 7 for different $\Delta \varphi$, which are consistent with the algebraic calculations shown in Table 2. Taking the red line shown in Figure 7 as an example, the RMS is about $4600 \mathrm{~V}$ in the steady-state which is consistent with the value obtained from (13). 


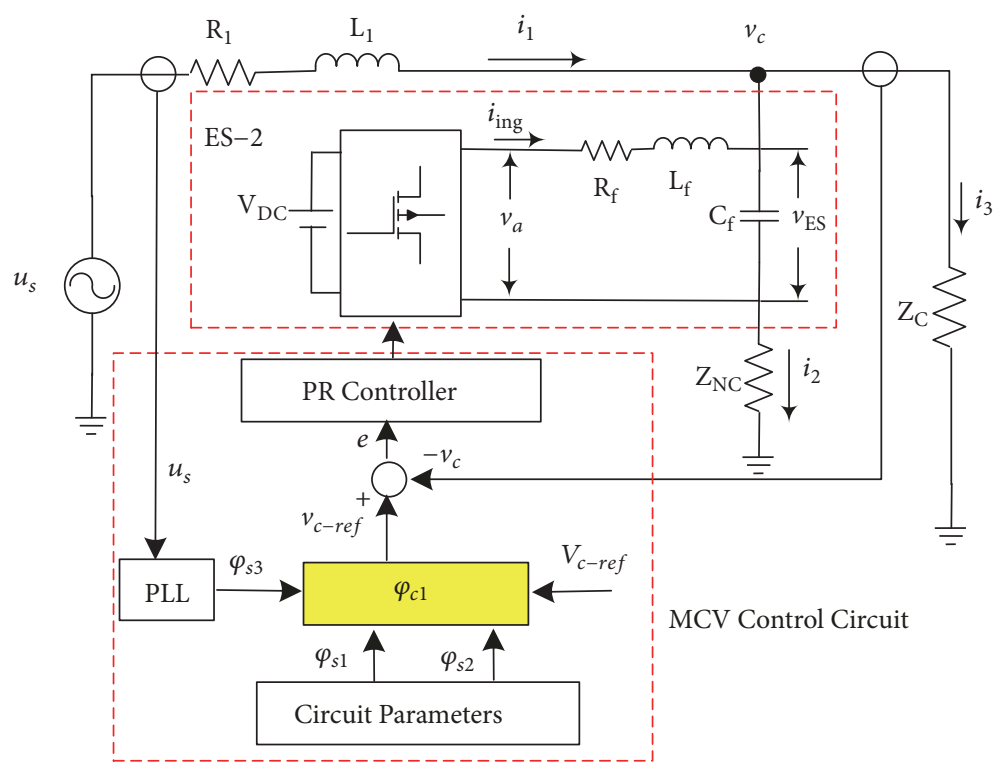

FIGURE 5: System block diagram of PR-controlled ES-2.

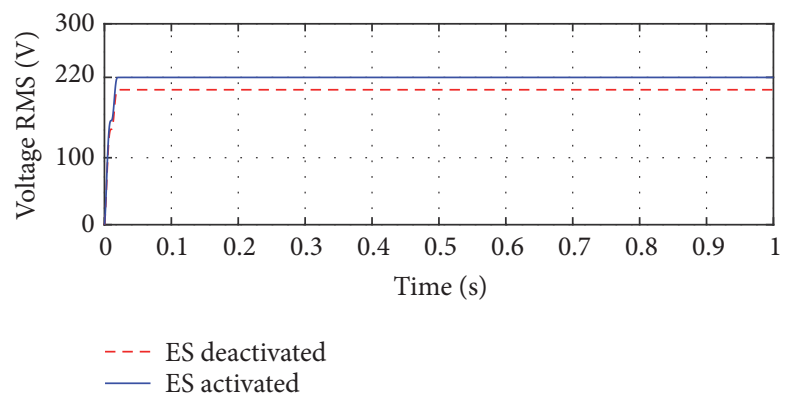

FIGURE 6: RMS of $v_{c}$ with ES-2 deactivated and activated when $\Delta U=$ $0 \mathrm{~V}$.

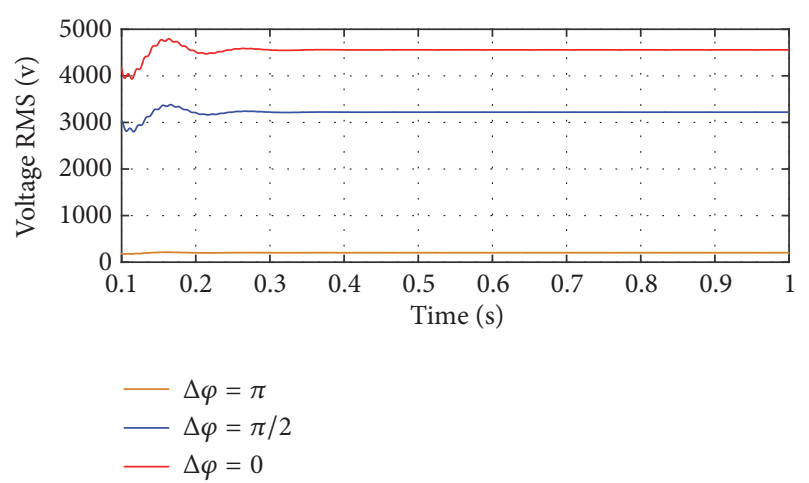

FIGURE 7: RMS of $v_{e s}$ of regulating $v_{c}$ to the rated value under different $\Delta \varphi$.

5.1.2. Voltage Suppression Mode with $\Delta U=30 \mathrm{~V}$. In this case study, the effect of different $\Delta \varphi$ on $V_{e s}$ for voltage suppression is investigated. Figure 8 shows the RMS of the line voltage $v_{c}$ with ES-2 activated and deactivated when $\Delta U=30$, which is used to simulate the overvoltage conditions. When $\Delta U=30$, the RMS of the line voltage $v_{c}$ is about 230

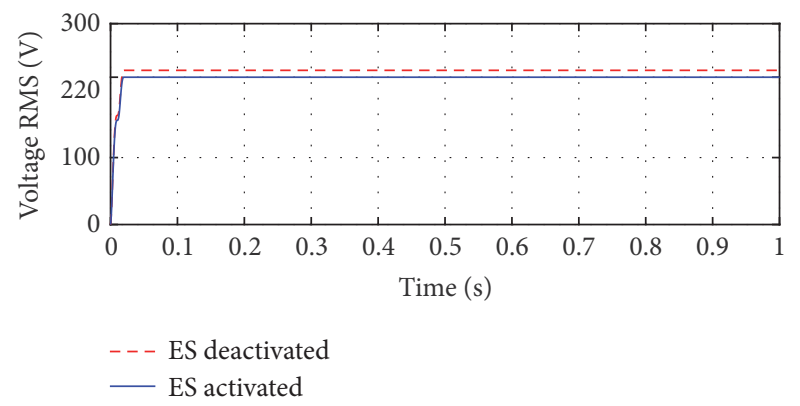

FIGURE 8: RMS of $v_{c}$ with ES-2 deactivated and activated when $\Delta U=$ $30 \mathrm{~V}$.

$\mathrm{V}$ with ES-2 deactivated. However, under the action of the ES-2, $V_{c}$ is effectively controlled at $220 \mathrm{~V}$. Similarly, for different $\Delta \varphi$, the compensating voltage injected to the power system is considerably different as shown in Figure 9. The simulation results correspond to the analyses mentioned in Section 3. As previously mentioned, for ES-1, the compensating capability is limited [19]. For example, by using the parameters in Table 1, it has been described in [27] that the variation range of $U_{s}$ is $215.8 \mathrm{~V}$ to $236.7 \mathrm{~V}$, which means that, if $U_{s}$ is out of the range mentioned above, ES- 1 cannot regulate $V_{c}$ at $220 \mathrm{~V}$. When $\Delta U=0 \mathrm{~V}$, that is to say $U_{s}$ is $210 \mathrm{~V}$, one can intuitively see that ES-1 can just adjust the voltage to $214 \mathrm{~V}$ as shown in Figure 10. Similarly, when $\Delta U=30 \mathrm{~V}$, which means that the supply voltage is higher than the upper compensation limit of ES-1, ES-1 can just adjust the voltage to $223 \mathrm{~V}$ in the best case. Such a fact indicates that ES-2 has a larger compensation range than ES-1. In some cases where the voltage fluctuation is large, ES-1 may fail to regulate the line voltage $v_{c}$, whereas ES-2 does.

5.1.3. ES-1 vs ES-2 within the Effective Regulation Range of ES-1. In this case study, ES voltage, compensation modes, 


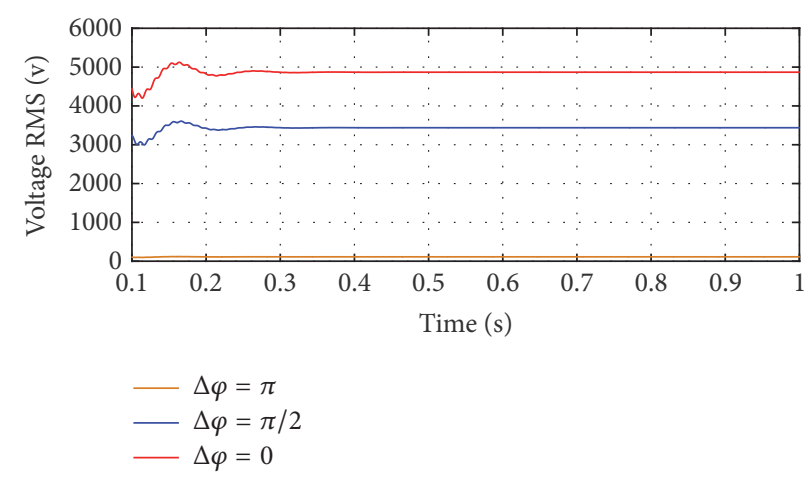

Figure 9: RMS of $v_{e s}$ of regulating $v_{c}$ to the rated value under different $\Delta \varphi$.

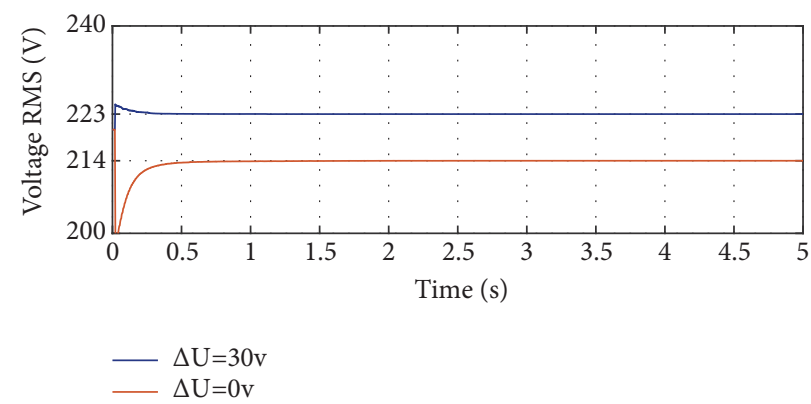

FIGURE 10: RMS of $v_{c}$ with ES-1 activated when $\Delta U=0 \mathrm{~V}$ and $\Delta U=30 \mathrm{~V}$.

and real and reactive powers are compared between ES-1 and ES-2 within the effective regulation range of ES-1. From Figure 11(a), one can see the ES voltages of ES-1 and ES-2 with the supply voltage $U_{s}=216 \mathrm{~V}$, respectively, where the voltage of ES-2 (about $140 \mathrm{~V}$ ) based on the MCV control strategy is less than the voltage of ES-1 (about $162 \mathrm{~V}$ ) to regulate the line voltage $v_{c}$ to $220 \mathrm{~V}$. If one carefully observes the phase relationships in Figures 11(b) and 11(c), one will find that the ES-1 voltage lags its current about 90 degrees for capacitive compensation. Therefore, the real and reactive power of ES-1 are about 0 and -3000 Var as shown in Figures 11(d) and 11(e), respectively. For ES-2, its voltage lags its current by more than 90 degrees for negative resistive plus capacitive compensation. Therefore, ES-2 injects about 3600 Var reactive power, while injecting about $1200 \mathrm{~W}$ real power at the same time to regulate the line voltage to its rated value as shown in Figures 11(d) and 11(e).

Similarly, ES-1 and ES-2 are also compared in voltage suppression mode within the effective regulation range of ES-1. The ES voltages of ES-1 and ES-2 are about $97 \mathrm{~V}$ and $70 \mathrm{~V}$ with the supply voltage $U_{s}=236 \mathrm{~V}$ as shown in Figure 12(a). As can be seen from Figures 12(b) and 12(c), the ES- 2 voltage leads its current by more than 90 degrees for negative resistive plus inductive compensation, while ES1 is in inductive compensation mode to suppress voltage. Figures $12(\mathrm{~d})$ and $12(\mathrm{e})$ show the corresponding real and reactive power injected into the power grid. One remark is that the ES currents in Figures 11(b), 11(c), 12(b), and 12(c) are enlarged for the ease of comparison while maintaining the phases.
The simulation results not only verify the effectiveness of the steady-state analysis and the MCV control scheme, but also show that ES-2 has a remarkable ability to regulate the PCC voltage. Theoretically, ES-2 has a wider range of compensation with respect to ES-1, in the sense that for any $\Delta U$, there always exists a corresponding $V_{e s}$ to regulate $V_{c}$ at its nominal level. In addition to this, the ES-2 voltage is less than the ES-1 voltage within the effective regulation range of ES-1 at the expense of some real power.

5.2. The Simulations Conducted on LabVIEW/PXI. To further verify the effectiveness of the steady-state analysis in Section 3 and the MCV control strategy in Section 4, hardware in the loop (HIL) simulations are conducted based on LabVIEW/PXIe-1071. For convenience, the ES currents shown in the following simulation results are actually the voltages across the noncritical roads. Since the current and the voltage of the resistive load are in the same phase, it does not affect the verification of the phase relationship.

5.2.1. The Influence of $\Delta \varphi$ on $v_{e s}$. In this case study, the influence of $\Delta \varphi$ on $v_{e s}$ with $\Delta U \stackrel{=}{=} 0 \mathrm{~V}$ and $\Delta U=30 \mathrm{~V}$ is further analyzed. From Figures 13(a), 13(c), and 13(e), we can see intuitively the sine waveforms of voltage $v_{e s}$, whose RMS values are $4.587 \mathrm{~V}, 3.29 \mathrm{~V}$, and $207.7 \mathrm{mV}$ with $\Delta \varphi=0$, $\Delta \varphi=(1 / 2) \pi$, and $\Delta \varphi=\pi$ when $\Delta U=0 \mathrm{~V}$, respectively. It is worth noting that RMS values here are reduced by 1000 times due to the fact that HIL output constraint is $\pm 10 \mathrm{~V}$. Similarly, when $\Delta U=30$, the corresponding RMS values are 4.901 V, $3.431 \mathrm{~V}$, and $114.0 \mathrm{mV}$ as shown in Figures 13(b), 13(d), 


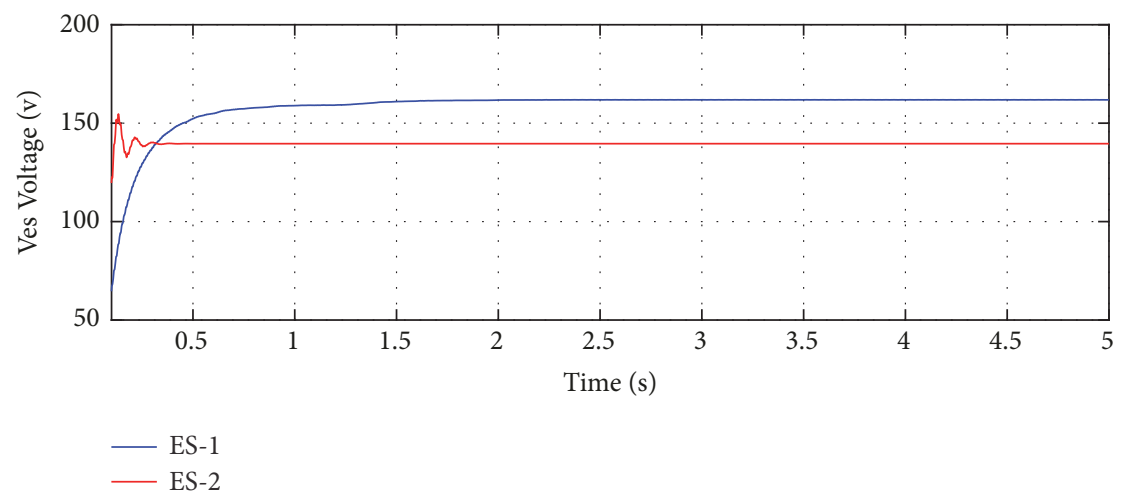

(a)

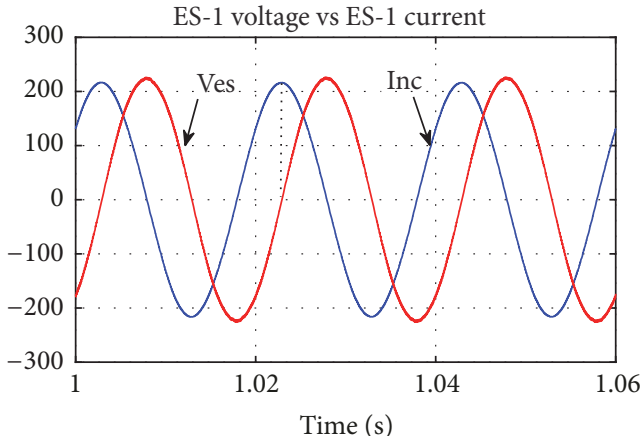

(b)

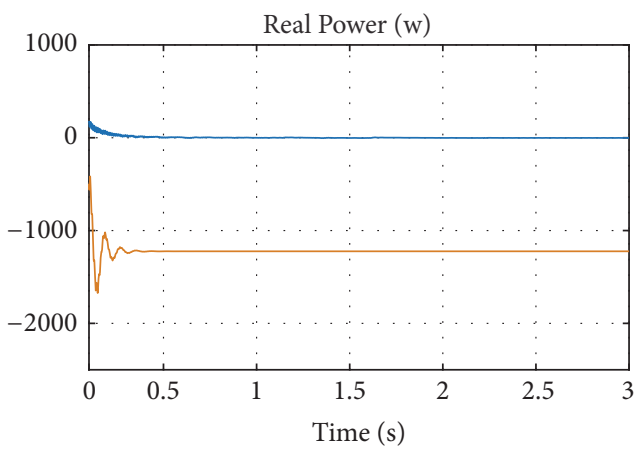

ES-1

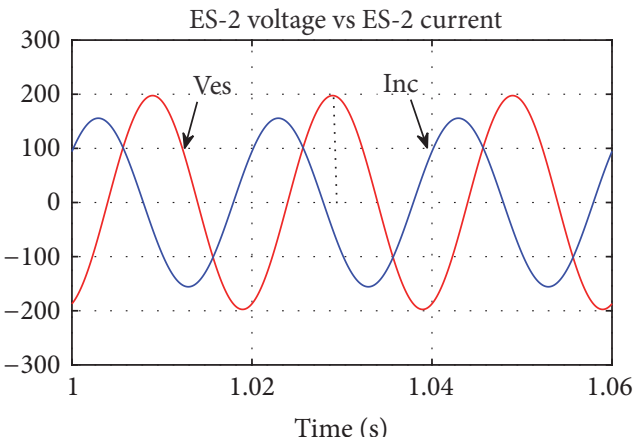

(c)

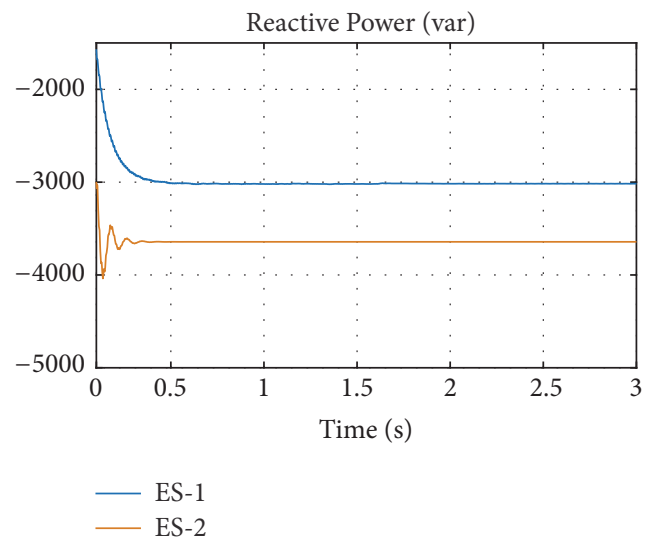

(e)

FIgURE 11: Comparing ES-1 with ES-2 when $U_{s}=216$ V. (a) ES voltage; (b) ES-1 voltage vs ES-1 current; (c) ES-2 voltage vs ES-2 current; (d) real power; (e) reactive power. (All the current amplitudes are enlarged for the ease of comparison while maintaining the phases.)

and 13(f), respectively. The results of the HIL simulations and the Matlab simulations as well as the theoretical calculations are basically consistent, which means that $v_{e s}$ is extremely sensitive to $\Delta \varphi$. Moreover, it further indicates the necessity of MCV control strategy for ES-2 to regulate the line voltage due to the fact that DC side voltage of ES- 2 is constrained.

\subsubsection{Comparing ES-1 with ES-2 out of the Effective Regulation} Range of ES-1. From the perspective of power electronics, ES1 is a special reactive power compensator used to regulate the line voltage in the future smart grid with multiple renewable energy sources. However, due to the limitation of its compensation modes, only reactive power is exchanged with the power grid; thus ES-1 has compensation limits. In other words, once the supply voltage changes beyond a certain range, ES-1 will fail. With the introduction of real power for voltage regulation, ES-2 can well overcome this disadvantage. In this case study, the supply voltage is set at $U_{s}=240 \mathrm{~V}$, which is out of the effective regulation range of ES-1. Figures 14(a) and 14(b) show the line voltage $v_{c}$ with ES-1 and ES-2 activated, respectively. The RMS values, 4.47 $\mathrm{V}$ and $4.39 \mathrm{~V}$, in Figures 14(a) and 14(b) are reduced by 50 times, which show that the ES-1 is unable to adjust $v_{c}$ to its rated value. The phase relation in Figure 14(c) indicates ES-1 


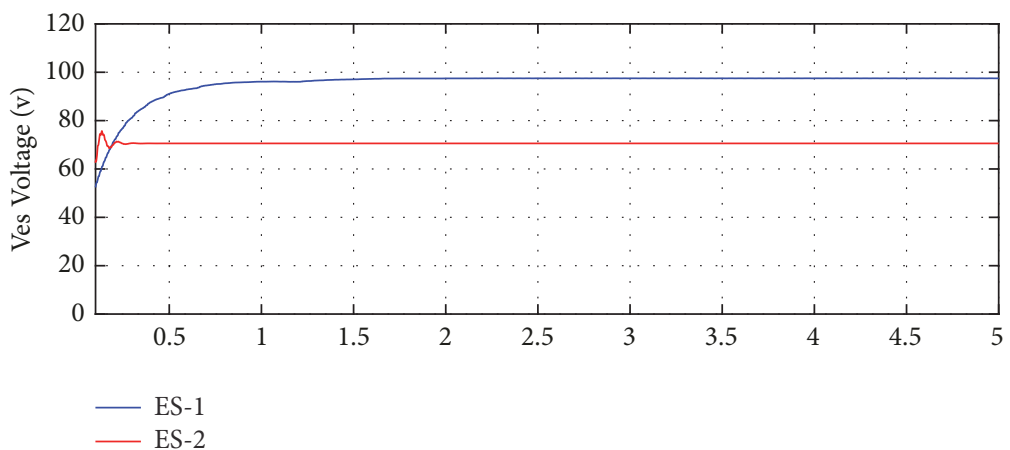

(a)

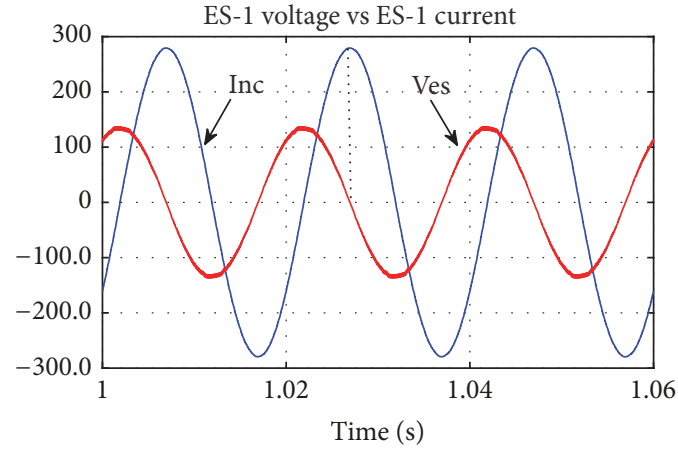

(b)
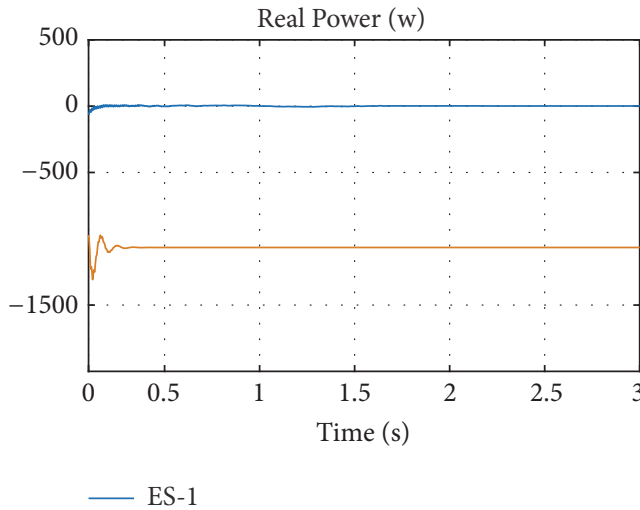

ES-2

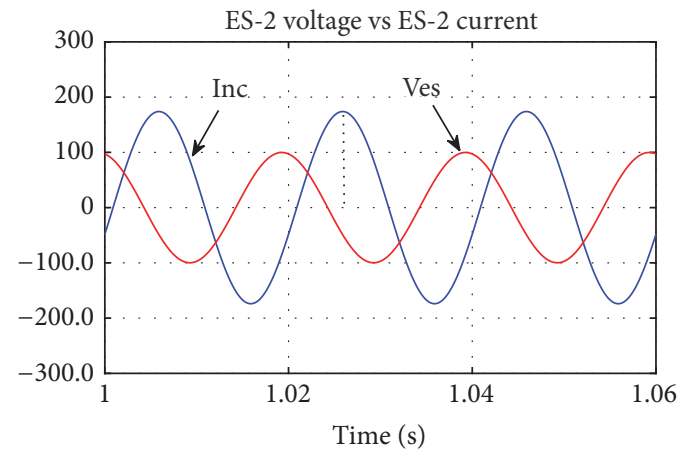

(c)

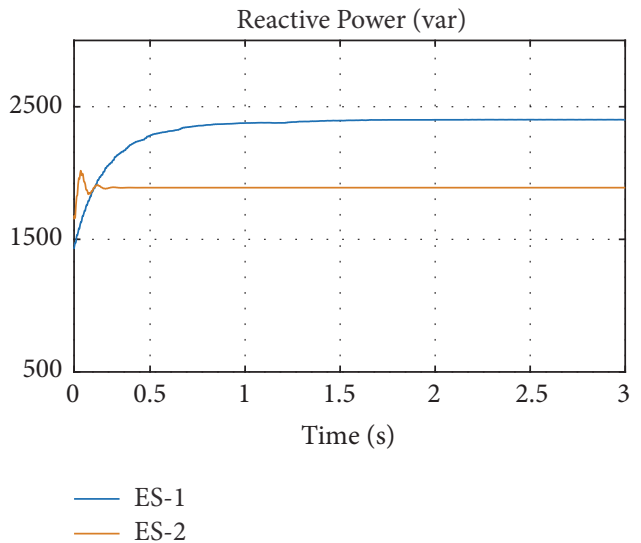

(e)

FIGURE 12: Comparing ES-1 with ES-2 when $U_{s}=236$ V. (a) ES voltage; (b) ES-1 voltage vs ES-1 current; (c) ES-2 voltage vs ES-2 current; (d) real power; (e) reactive power. (All the current amplitudes are enlarged for the ease of comparison while maintaining the phases.)

is in inductive compensation mode, while ES-2 is in negative resistive plus inductive compensation mode as shown in Figure 14(d).

5.2.3. ES-1 and ES-2 for Voltage Boosting within the Effective Regulation Range of ES-1. ES-1 and ES-2 are compared for voltage boosting within the effective regulation range of ES1 in this case study. The supply voltage is set at $U_{s}=216 \mathrm{~V}$, which is within the effective regulation range of ES-1 and used to simulate undervoltage conditions. The phase relationships of ES-1 and ES-2 are shown in Figures 15(a) and 15(c), while the corresponding output voltages of ES-1 and ES-2 are shown in Figures 15(b) and 15(d), respectively. The simulation results show that the ES-2 based on the MCV control strategy has a smaller output voltage relative to ES-1 at the expense of injecting some real power to the power grid for voltage boosting.

\subsubsection{ES-1 and ES-2 for Voltage Suppression within the Effective} Regulation Range of ES-1. Similar to the voltage boosting mode, ES-1 and ES-2 are compared for voltage suppression within the effective regulation range of ES-1 in this case study. The supply voltage is set at $U_{s}=236 \mathrm{~V}$, which is within the effective regulation range of ES-1 and used to simulate overvoltage conditions. As can be seen from Figure 16(a), the ES-1 voltage and ES-1 current are almost orthogonal and ES-1 voltage leads ES-1 current by almost 90 degrees for inductive compensation to suppress voltage, while the 


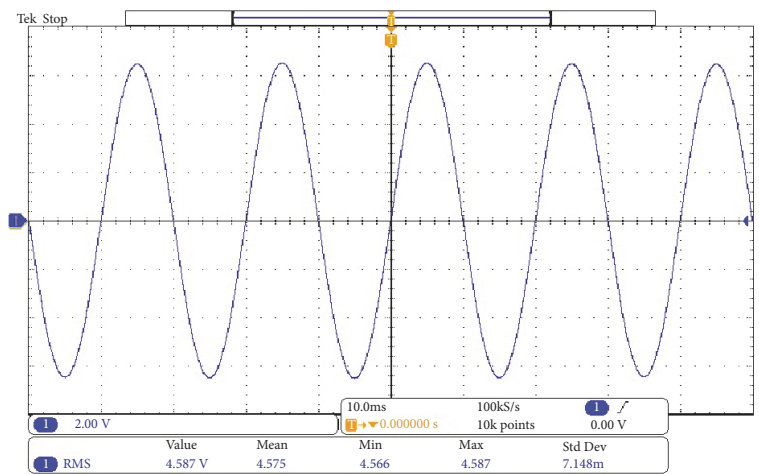

(a)

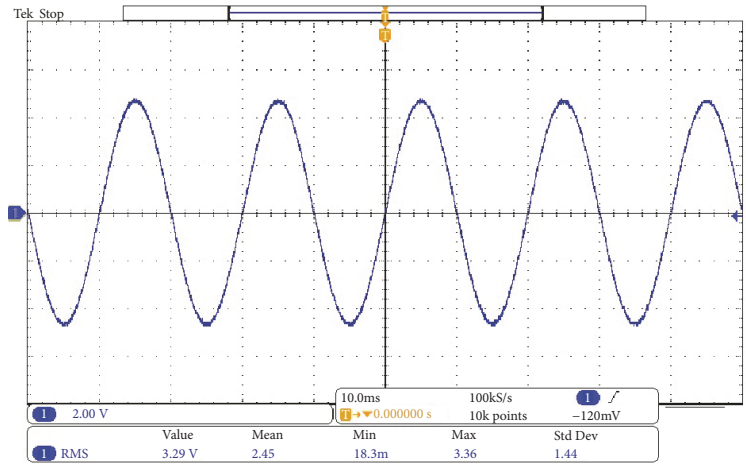

(c)

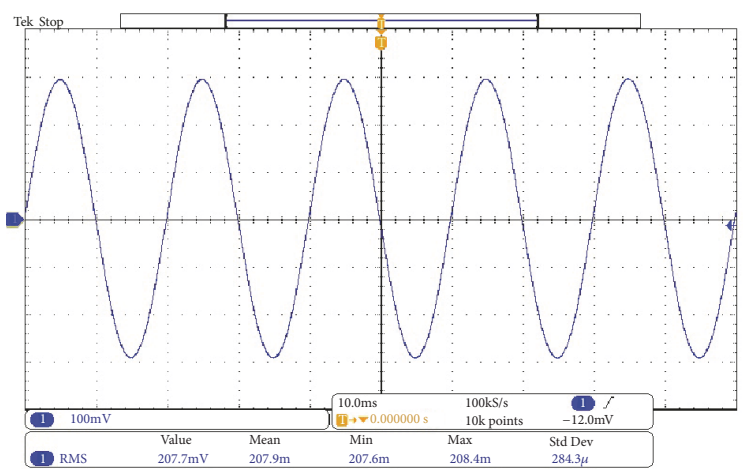

(e)

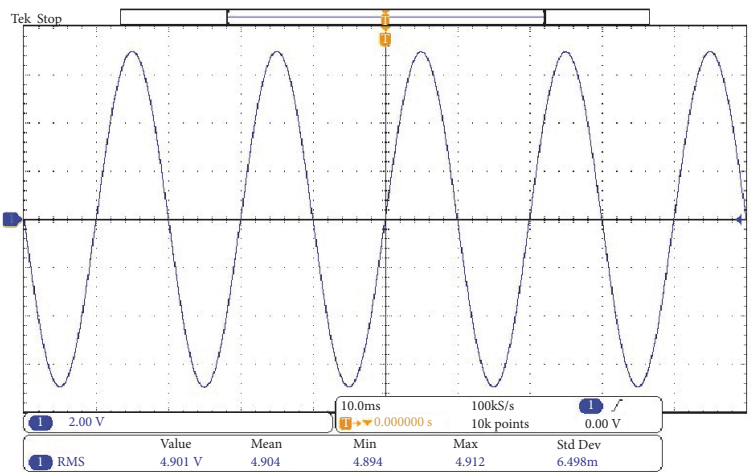

(b)

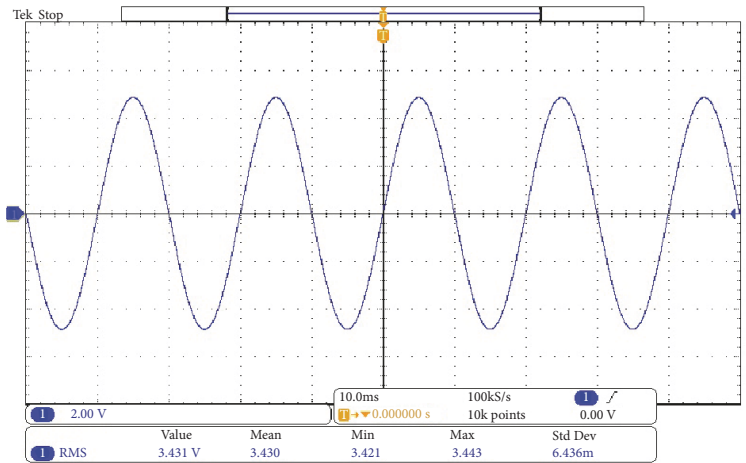

(d)

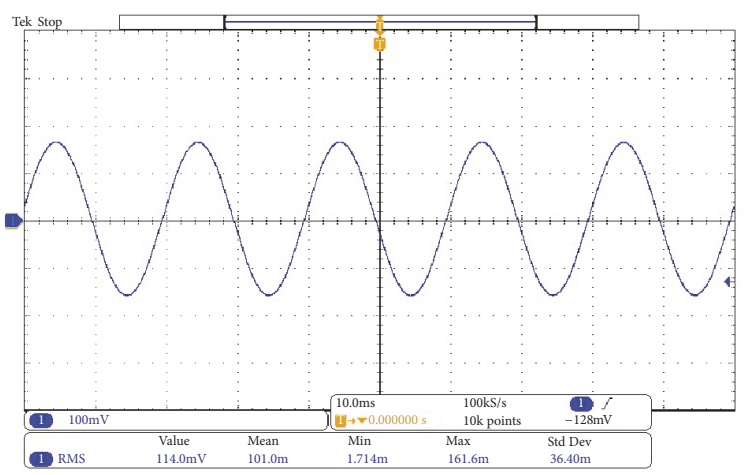

(f)

FIGURE 13: Sine waveforms of voltage $v_{e s}$ when $\Delta U=0 \mathrm{~V}$ and $\Delta U=30 \mathrm{~V}$. (a) ES voltage when $\Delta \varphi=0$ and $\Delta U=0 \mathrm{~V}$; (b) ES voltage when $\Delta \varphi=0$ and $\Delta U=30 \mathrm{~V}$; (c) ES voltage when $\Delta \varphi=(1 / 2) \pi$ and $\Delta U=0 \mathrm{~V}$; (d) ES voltage when $\Delta \varphi=(1 / 2) \pi$ and $\Delta U=30 \mathrm{~V}$; (e) ES voltage when $\Delta \varphi=\pi$ and $\Delta U=0 \mathrm{~V}$; (f) ES voltage when $\Delta \varphi=\pi$ and $\Delta U=30 \mathrm{~V}$.

corresponding ES-1 voltage is shown in Figure 16(b). ES2 works in negative resistive plus inductive compensation mode based on the MCV control strategy as shown in Figure 16(c), while its output voltage injected to the power grid is shown in Figure 16(d). In the same way, ES-2 based on the MCV control strategy has a smaller output voltage relative to ES-1.

\section{Conclusion}

ES-1 has compensation limits because of the constraints of its structure, while ES-2 can effectively remedy this defect at the expense of injecting real power. In this paper,
ES-1 and ES-2 were compared in detail within and out of the effective regulation range. Moreover, for ES-2, the steadystate analysis was provided and a PR-based MCV control strategy was proposed to regulate the PCC voltage. For steady-state analysis, the relationship among the fluctuating part of the supply voltage, the PCC voltage, and the compensating voltage provided by ES- 2 was derived, which implied that the phase angle of the PCC voltage could be used as a degree of freedom for control design to obtain a minimal compensating voltage in a given system. Once the phase angle of the PCC voltage was chosen, the maximal compensating voltage could be estimated based on the fluctuating part of the supply voltage which could be estimated a priori. 


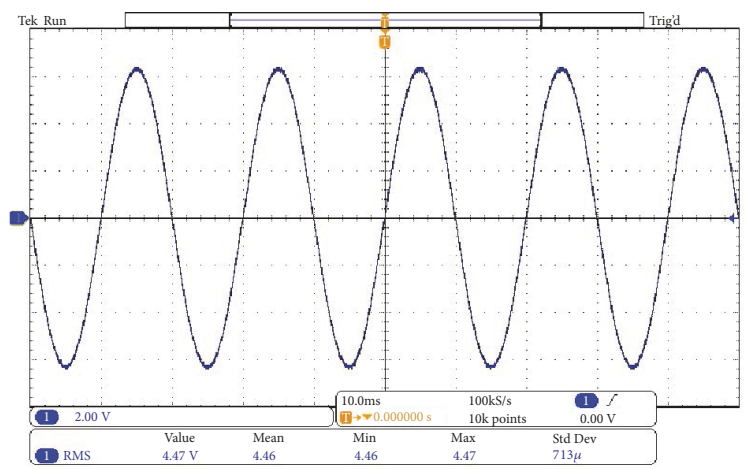

(a)

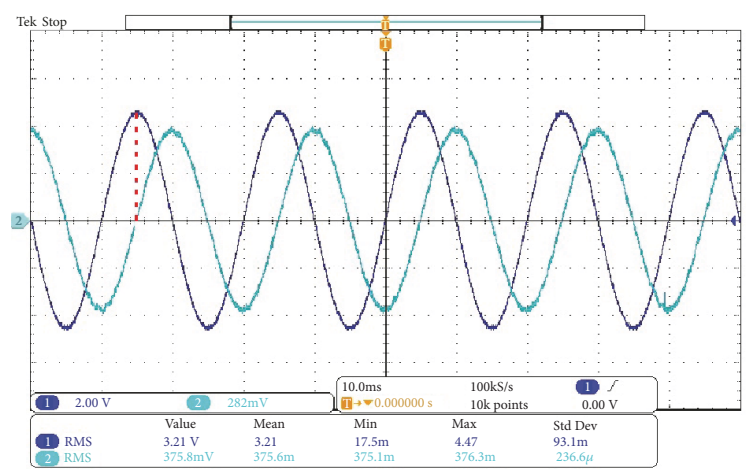

(c)

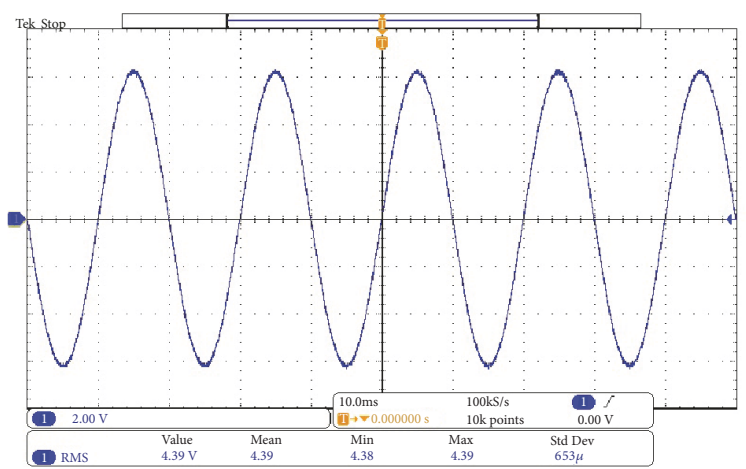

(b)

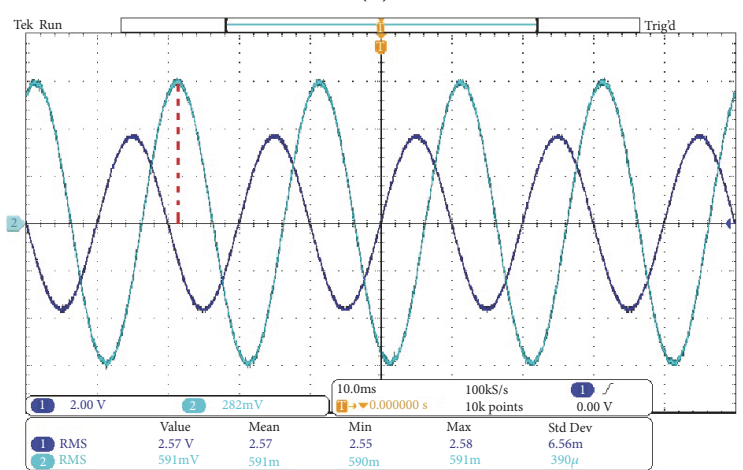

(d)

FIGURE 14: Comparing ES-1 with ES-2 when $U_{s}=240$ V. (a) $v_{c}$ with ES-1 activated; (b) $v_{c}$ with ES-2 activated; (c) ES-1 voltage vs ES-1 current; (d) ES-2 voltage vs ES-2 current. (All the indicated ES currents are represented by the voltages of the resistive noncritical loads for the ease of comparison because of the same phase of the ES currents and the voltages of the resistive noncritical loads.)

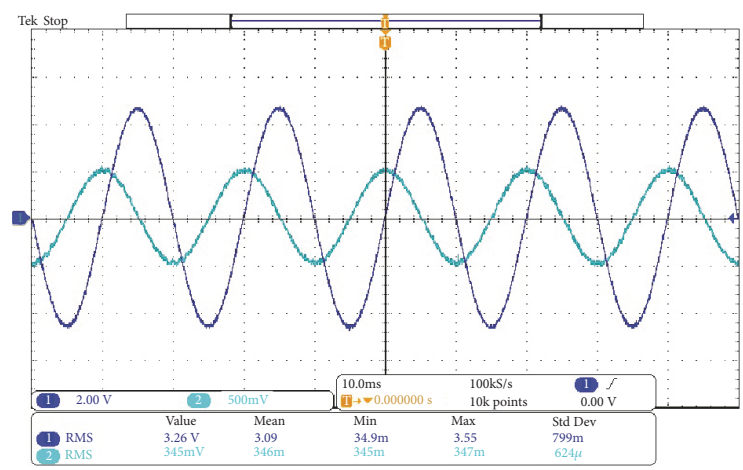

(a)

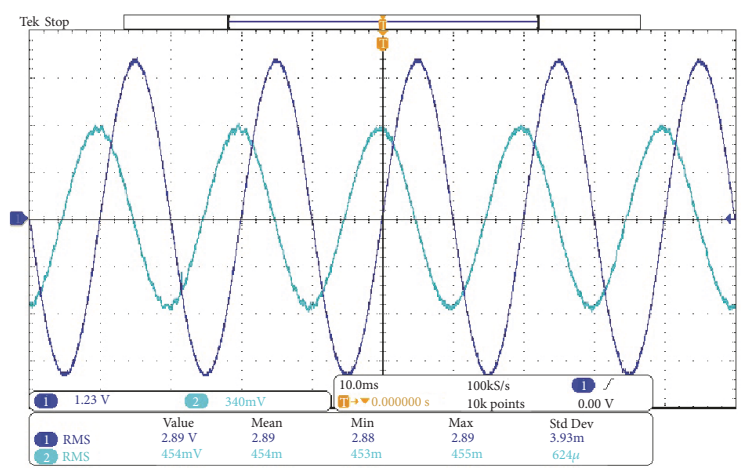

(c)

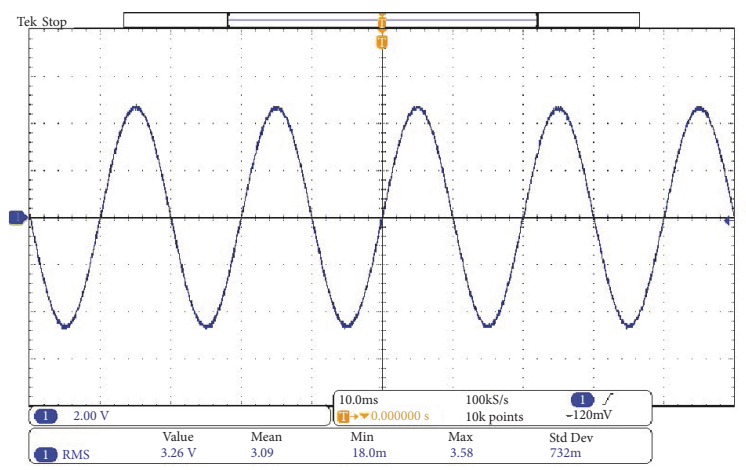

(b)

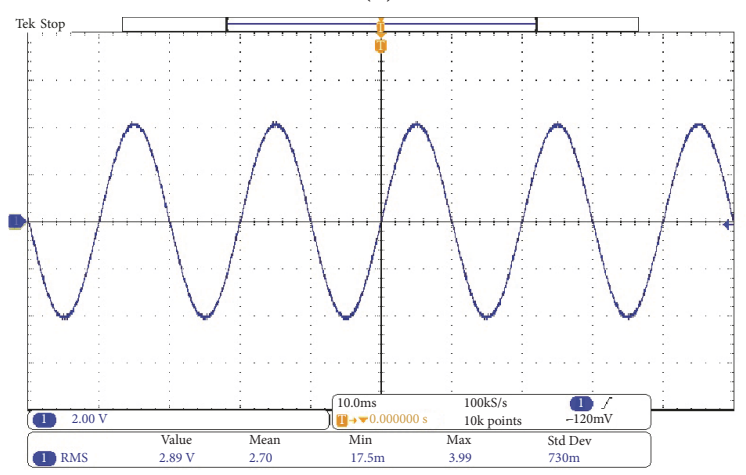

(d)

FIGURE 15: Comparing ES-1 with ES-2 when $U_{s}=216$ V. (a) ES-1 voltage vs ES-1 current; (b) ES-1 voltage; (c) ES-2 voltage vs ES-2 current; (d) ES-2 voltage. (All the indicated ES currents are represented by the voltages of the resistive noncritical loads for the ease of comparison because of the same phase of the ES currents and the voltages of the resistive noncritical loads.) 


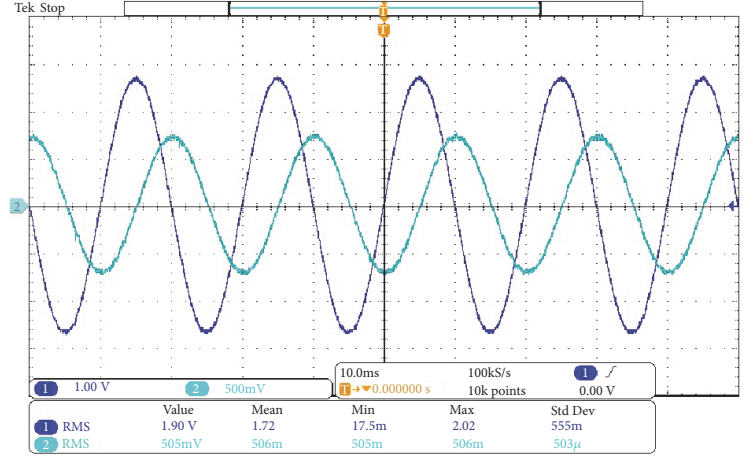

(a)

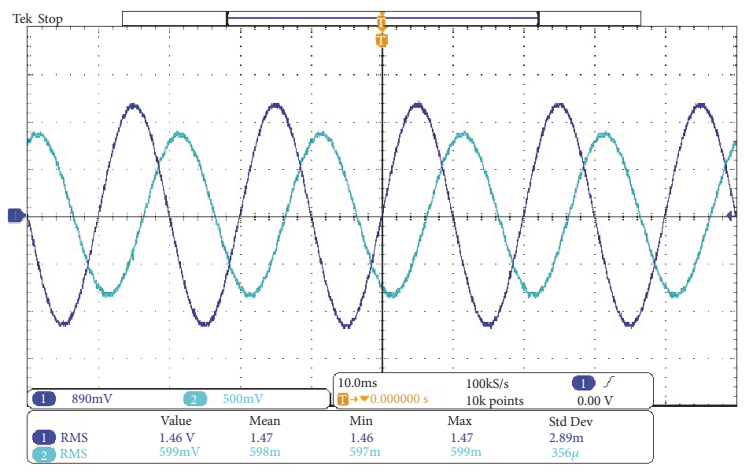

(c)

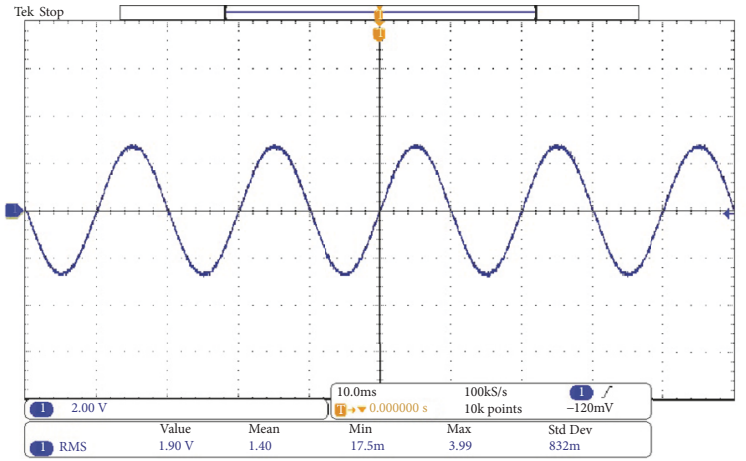

(b)

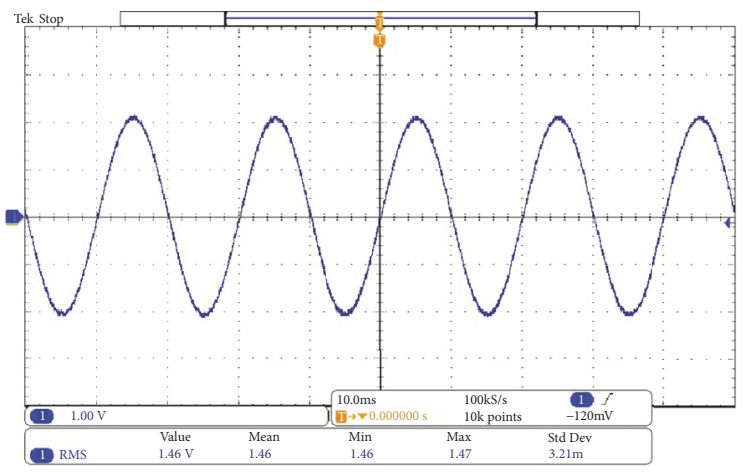

(d)

Figure 16: Comparing ES-1 with ES-2 when $U_{s}=236$ V. (a) ES-1 voltage vs ES-1 current; (b) ES-1 voltage; (c) ES-2 voltage vs ES-2 current; (d) ES-2 voltage. (All the indicated ES currents are represented by the voltages of the resistive noncritical loads for the ease of comparison because of the same phase of the ES currents and the voltages of the resistive noncritical loads.)

Such a fact could be used for designing suitable electric springs with appropriate compensating capacity. Numerical simulations were conducted to demonstrate the effectiveness of the steady-state analysis and the control scheme.

\section{Data Availability}

All data can be accessed in the Simulation Studies section of this article.

\section{Conflicts of Interest}

The authors declare that there are no conflicts of interest regarding the publication of this article.

\section{Acknowledgments}

This research was supported by the National Natural Science Foundation of China [grant number 61873129].

\section{References}

[1] Y. Zhao, C. Wei, Z. Zhang, and W. Qiao, "A review on position/speed sensorless control for permanent-magnet synchronous machine-based wind energy conversion systems," IEEE Journal of Emerging and Selected Topics in Power Electronics, vol. 1, no. 4, pp. 203-216, 2013.
[2] Q. Guo, Z. Sun, Y. Zhang, and W. Xu, "Time-delayed feedback control in the multiple attractors wind-induced vibration energy harvesting system," Complexity, vol. 2019, Article ID 7973823, 11 pages, 2019.

[3] F. Cheng, L. Qu, W. Qiao, C. Wei, and L. Hao, "Fault diagnosis of wind turbine gearboxes based on dfig stator current envelope analysis," IEEE Transactions on Sustainable Energy, 2018.

[4] T. Kang, S. Kim, C. Hyoung, S. Kang, and K. Park, "An energy combiner for a multi-input energy-harvesting system," IEEE Transactions on Circuits and Systems II: Express Briefs, vol. 62, no. 9, pp. 911-915, 2015.

[5] K. T. Tan, X. Y. Peng, P. L. So, Y. C. Chu, and M. Z. Q. Chen, "Centralized control for parallel operation of distributed generation inverters in microgrids," IEEE Transactions on Smart Grid, vol. 3, no. 4, pp. 1977-1987, 2012.

[6] H. E. Espitia, I. Machón-González, H. López-García, and G. Díaz, "Proposal of an adaptive neurofuzzy system to control flow power in distributed generation systems," Complexity, vol. 2019, Article ID 1610898, 16 pages, 2019.

[7] Z. Yang, J. Xiang, and Y. Li, "Distributed consensus based supply-demand balance algorithm for economic dispatch problem in a smart grid with switching graph," IEEE Transactions on Industrial Electronics, vol. 64, no. 2, pp. 1600-1610, 2017.

[8] M. Pedrasa, T. Spooner, and I. MacGill, "Scheduling of demand side resources using binary particle swarm optimization," IEEE Transactions on Power Systems, vol. 24, no. 3, pp. 1173-1181, 2009.

[9] Z. Luo, J. Zhao, R. Yao, and Z. Shu, "Emergy-based sustainability assessment of different energy options for green buildings," Energy Conversion and Management, vol. 100, pp. 97-102, 2015. 
[10] L. Xi, Y. Li, Y. Huang, L. Lu, and J. Chen, "A novel automatic generation control method based on the ecological population cooperative control for the islanded smart grid," Complexity, vol. 2018, Article ID 2456963, 17 pages, 2018.

[11] H. Zhong, D. Du, C. Li, and X. Li, "A novel sparse false data injection attack method in smart grids with incomplete power network information," Complexity, vol. 2018, Article ID 8503825, 16 pages, 2018.

[12] S. Y. Hui, C. K. Lee, and F. F. Wu, "Electric springs - a new smart grid technology," IEEE Transactions on Smart Grid, vol. 3, no. 3, pp. 1552-1561, 2012.

[13] N. R. Chaudhuri, C. K. Lee, B. Chaudhuri, and S. Y. R. Hui, "Dynamic modeling of electric springs," IEEE Transactions on Smart Grid, vol. 5, no. 5, pp. 2450-2458, 2014.

[14] C. K. Lee, B. Chaudhuri, and S. Y. Hui, "Hardware and control implementation of electric springs for stabilizing future smart grid with intermittent renewable energy sources," IEEE Journal of Emerging and Selected Topics in Power Electronics, vol. 1, no. 1, pp. 18-27, 2013.

[15] C. Kwan Lee, N. Ray Chaudhuri, B. Chaudhuri, and S. Y. R. Hui, "Droop control of distributed electric springs for stabilizing future power grid," IEEE Transactions on Smart Grid, vol. 4, no. 3, pp. 1558-1566, 2013.

[16] X. Chen, Y. Hou, and S. Y. Ron Hui, "Distributed control of multiple electric springs for voltage control in microgrid," IEEE Transactions on Smart Grid, vol. 8, no. 3, pp. 1350-1359, 2017.

[17] S.-C. Tan, C. K. Lee, and S. Y. Hui, "General steady-state analysis and control principle of electric springs with active and reactive power compensations," IEEE Transactions on Power Electronics, vol. 28, no. 8, pp. 3958-3969, 2013.

[18] S. Yan, S.-C. Tan, C.-K. Lee, B. Chaudhuri, and S. Y. R. Hui, "Use of smart loads for power quality improvement," IEEE Journal of Emerging and Selected Topics in Power Electronics, vol. 5, no. 1, pp. 504-512, 2017.

[19] Q. Wang, M. Cheng, Z. Chen, and Z. Wang, "Steady-state analysis of electric springs with a novel $\delta$ control," IEEE Transactions on Power Electronics, vol. 30, no. 12, pp. 7159-7169, 2015.

[20] K.-T. Mok, S.-C. Tan, and S. Y. R. Hui, "Decoupled power angle and voltage control of electric springs," IEEE Transactions on Power Electronics, vol. 31, no. 2, pp. 1216-1229, 2016.

[21] L. Diao, H. Du, Z. Shu, Y. Xue, M. Li, and S. M. Sharkh, "A comparative study between AI-HM and SPD-HM for railway auxiliary inverter with pulsating DC link," IEEE Transactions on Industrial Electronics, vol. 65, no. 7, pp. 5816-5825, 2018.

[22] X. Liu, A. M. Cramer, and F. Pan, "Generalized average method for time-invariant modeling of inverters," IEEE Transactions on Circuits and Systems I: Regular Papers, vol. 64, no. 3, pp. 740-751, 2017.

[23] X. Yan, Z. Shu, and S. M. Sharkh, "Hybrid modelling and control of single-phase grid-connected NPC inverters," in Proceedings of the IEEE Applied Power Electronics Conference and Exposition (APEC), pp. 2223-2228, IEEE, Long Beach, CA, USA, 2016.

[24] J. Zeng, W. Qiao, C. Wei, and L. Qu, "A soft-switched threeport single-stage inverter for photovoltaic-battery systems," in Proceedings of the IEEE Energy Conversion Congress and Exposition, pp. 4568-4573, IEEE, Montreal, QC, Canada, 2015.

[25] X. Yan, Z. Shu, S. M. Sharkh, and T. Chen, "Output-feedback switching control of DC-DC cuk converters using multiple sampling," in Proceedings of the International Automatic Control Conference (CACS), pp. 1-6, Yilan, Taiwan, 2015.
[26] J. Xiang, F. Ji, H. Nian, J. Zhang, and H. Deng, "Seamless transfer of single-phase utility interactive inverters with a synchronized output regulation strategy," Journal of Power Electronics, vol. 16, no. 5, pp. 1821-1832, 2016

[27] X. Wei, Y. Liu, Z. Zhang, and J. Wang, "Steady-state analysis of electric spring for smart grid," in Proceedings of the 12th World Congress on Intelligent Control and Automation (WCICA), pp. 905-909, Guilin, China, 2016.

[28] S. Wen, T. Huang, X. Yu, M. Z. Q. Chen, and Z. Zeng, "Slidingmode control of memristive chuas systems via the event-based method," IEEE Transactions on Circuits and Systems II: Express Briefs, vol. 64, no. 1, pp. 911-915, 2017.

[29] C. Wei, W. Qiao, and Y. Zhao, "Sliding-mode observer-based sensorless direct power control of DFIGs for wind power applications," in Proceedings of the IEEE Power and Energy Society General Meeting, (PESGM), IEEE, Denver, CO, USA, 2015.

[30] Y. Tang, H. Gao, and J. Kurths, "Distributed robust synchronization of dynamical networks with stochastic coupling," IEEE Transactions on Circuits and Systems I: Regular Papers, vol. 61, no. 5, pp. 1508-1519, 2014.

[31] Y. Xue, D. Meng, S. Yin et al., "Vector-based model predictive hysteresis current control for asynchronous motor," IEEE Transactions on Industrial Electronics, 2018.

[32] K. T. Tan, P. L. So, Y. C. Chu, and M. Z. Q. Chen, “Coordinated control and energy management of distributed generation inverters in a microgrid," IEEE Transactions on Power Delivery, vol. 28, no. 2, pp. 704-713, 2013.

[33] L. Zhang, M. Z. Chen, H. Su, and G. Chen, "Event-based asynchronous communication and sampled control for synchronization of multiagent networks with input saturation," International Journal of Robust and Nonlinear Control, vol. 28, no. 5, pp. 1871-1885, 2018. 


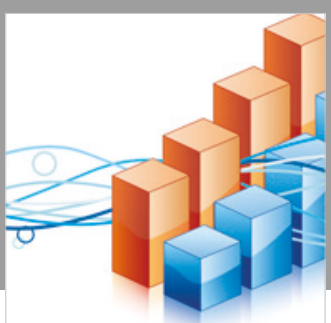

Advances in

Operations Research

\section{-n-m}
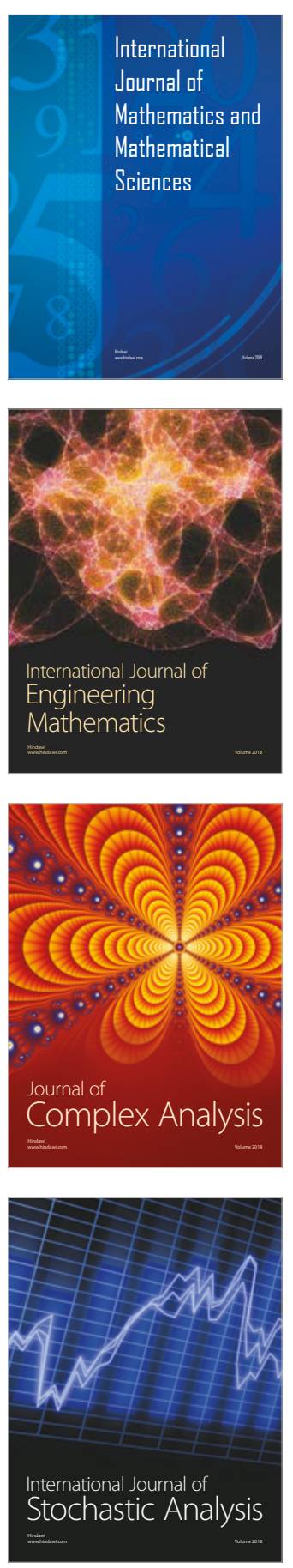
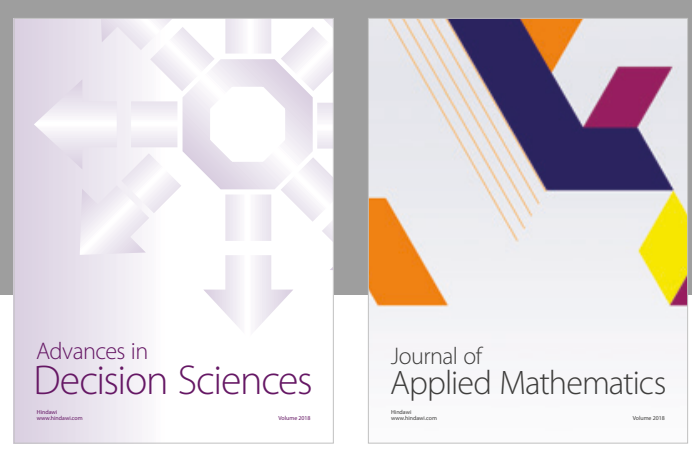

Journal of

Applied Mathematics
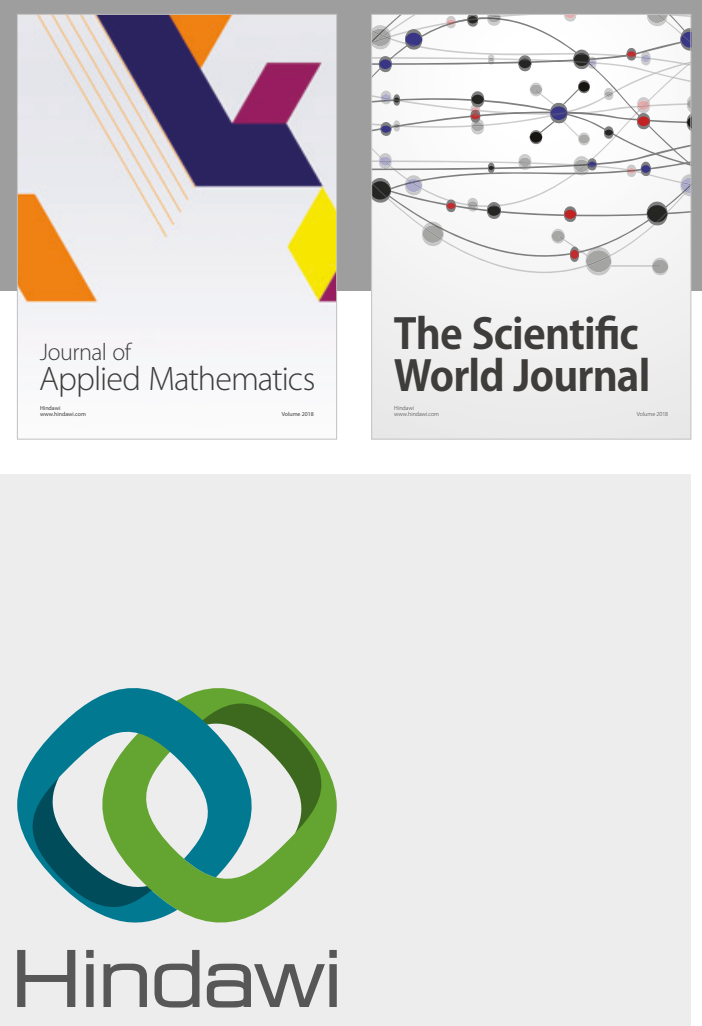

Submit your manuscripts at

www.hindawi.com

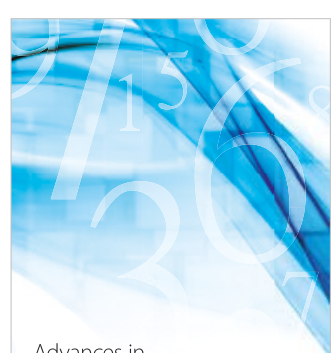

Advances in
Numerical Analysis
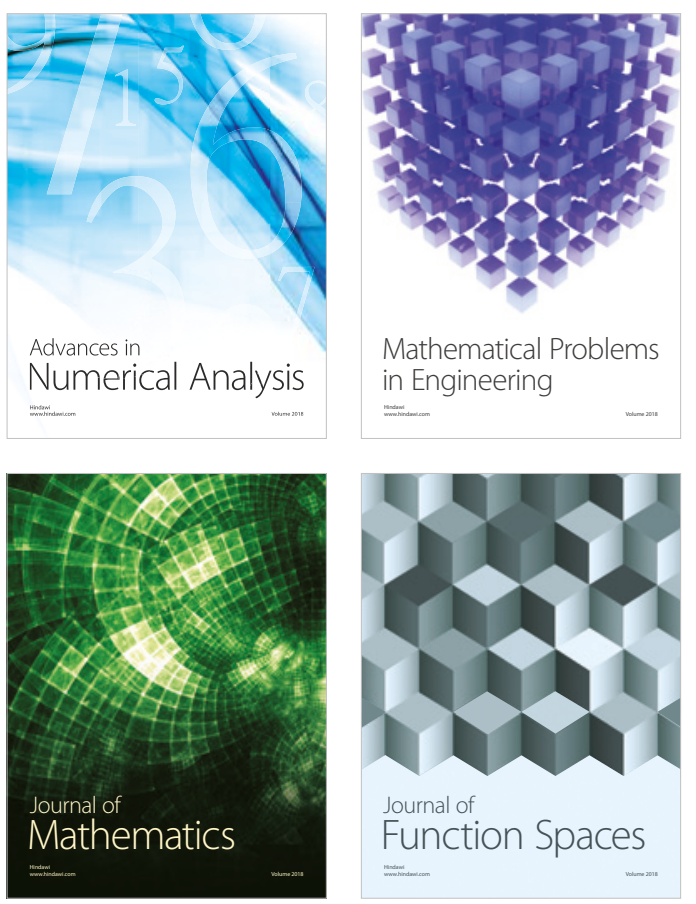

Mathematical Problems in Engineering

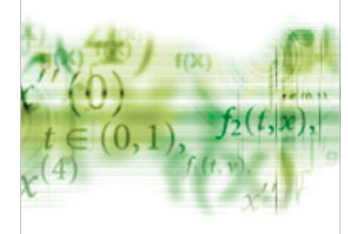

International Journal of

Differential Equations

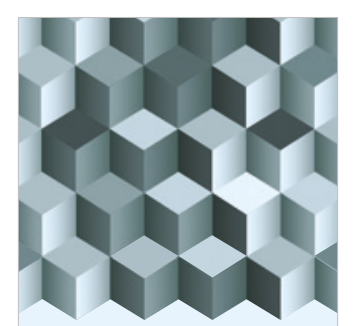

Journal of

Function Spaces
The Scientific

World Journal

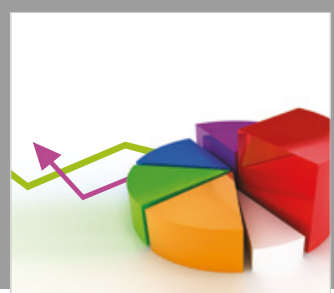

Journal of

Probability and Statistics
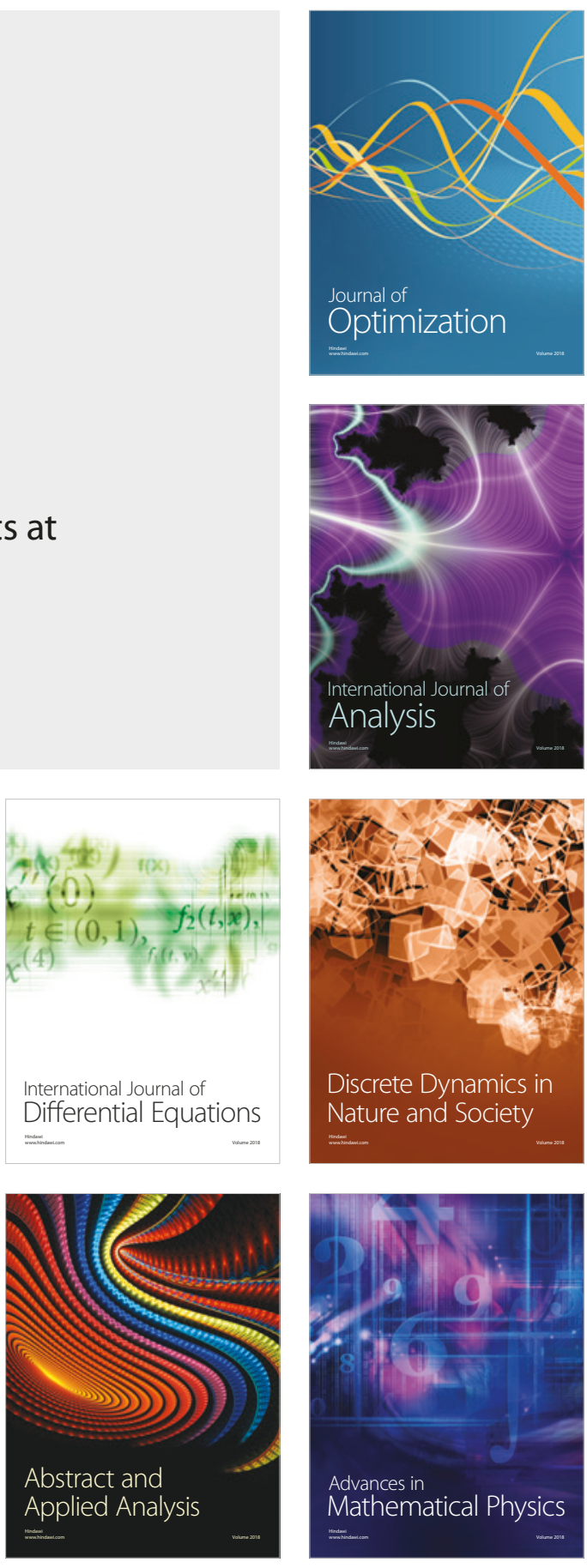